\title{
Prevalence of asthma among the adult general population of five Middle Eastern countries: results of the SNAPSHOT program
}

Hesham Tarraf ${ }^{1}$, Omur Aydin², Dilsad Mungan², Mohammad Albader ${ }^{3}$, Bassam Mahboub $^{4,5}$, Adam Doble ${ }^{6}$, Aaicha Lahlou', Luqman Tariq ${ }^{8}$, Fayaz Aziz ${ }^{8}$ and Abdelkader El Hasnaoui ${ }^{8^{*}}$ (I)

\begin{abstract}
Background: Asthma is a common chronic respiratory disease leading to morbidity, mortality and impaired quality of life worldwide. Information on asthma prevalence in the Middle East is fragmented and relatively out-dated. The SNAPSHOT program was conducted to obtain updated information.

Methods: SNAPSHOT is a cross-sectional epidemiological program carried out in five Middle Eastern countries (Egypt, Turkey, Kuwait, Saudi Arabia, and the United Arab Emirates, the latter three grouped into a Gulf cluster) to collect data on asthma, allergic rhinitis, benign prostatic hyperplasia and bipolar disorder. The survey was carried out by telephone in a random sample of the adult general population with quotas defined according to country demographics. The analysis presented in this paper focuses on asthma. Subjects were screened for asthma based on criteria from the global Asthma Insights and Reality studies. Current prevalence (last 12 months) was estimated. Multivariate logistic regression analyses were used to investigate risk factors related to asthma and the association with allergic rhinitis and other co-morbidities. Quality of life was assessed using the three-level EQ-5D questionnaire.

Results: 2124 out of the 33,486 subjects enrolled in the SNAPSHOT program fulfilled the criteria for asthma. The adjusted prevalence of asthma ranged from 4.4\% [95\% Cl: 4.0-4.8\%] in Turkey, to 6.7\% [95\% Cl: 6.2-7.2\%] in Egypt and 7.6\% [95\% Cl: 7.1-8.0\%] in the Gulf cluster. Prevalence was higher $(p<0.0001)$ in women than men and increased with age $(p<0.0001)$. Co-morbidities occurred more frequently in asthma subjects compared to the non-asthma population (38\% vs. $15 \% p<0.0001)$. Subjects with asthma reported a lower $(p<0.0001)$ EQ-VAS score $(68.2 \pm 22.9)$ compared to the general population (78.1 \pm 17.5$)$. The risk factors associated with asthma were age, gender, country, and certain co-morbidities, namely respiratory, cardiovascular, gastrointestinal, nervous, and neurological diseases.

Conclusion: The observed adjusted prevalence of asthma in the Middle East ranges from $4.4 \%$ to $7.6 \%$, which is comparatively lower than the reported prevalence in Europe and North America. Asthma has a negative impact on quality of life, and is associated with high levels of co-morbid diseases, indicating a need for physicians to check for co-morbidities and ensure they are managed correctly in all asthma patients.
\end{abstract}

Keywords: Asthma, Prevalence, Middle East, SNAPSHOT, Quality of life, Co-morbidity

\footnotetext{
* Correspondence: abdelkader.a.el-hasnaoui@gsk.com

${ }^{8}$ GlaxoSmithKline, PO Box 50199, Dubai, United Arab Emirates

Full list of author information is available at the end of the article
}

(c) The Author(s). 2018 Open Access This article is distributed under the terms of the Creative Commons Attribution 4.0 International License (http://creativecommons.org/licenses/by/4.0/), which permits unrestricted use, distribution, and reproduction in any medium, provided you give appropriate credit to the original author(s) and the source, provide a link to the Creative Commons license, and indicate if changes were made. The Creative Commons Public Domain Dedication waiver (http://creativecommons.org/publicdomain/zero/1.0/) applies to the data made available in this article, unless otherwise stated. 


\section{Background}

Asthma is one of the most common chronic respiratory diseases and is a major public health issue globally, affecting people of all ages, genders and ethnicities. It is estimated that the number of people with asthma worldwide may be as high as 334 million according to a report from the Global Asthma Network published in 2014 [1]. Prevalence has been shown to vary widely both between countries and within countries, and has been steadily increasing alongside that of allergy, as modern lifestyles are adopted and communities become more urbanised, a trend that is predicted to continue over the next two decades [2]. For those people affected by the disease, it can be a cause of major disability and impact greatly on quality of life $[1,2]$.

Asthma prevalence has been widely studied globally. However, many of the studies focus on the childhood prevalence of the disease, notably the International Study of Asthma and Allergies in Childhood (ISAAC) studies [3, 4]. In adults, three large, international, epidemiological projects assessing the prevalence of asthma have been conducted to date: the European Community Respiratory Health Survey (ECRHS) [5]; the World Health Survey (WHS) [6]; and the Global Allergy and Asthma Network of Excellence (GA2LEN) study in Europe [7]. Additional studies have estimated the prevalence and management of asthma in specific geographical areas such as the Asthma Insights and Reality (AIR) surveys [8], all of which utilise similar methodology and have now been carried out in a number of Middle Eastern countries including Turkey [9] and the Gulf [10]. However, to improve the understanding of asthma prevalence worldwide, further international studies are needed and require use of a consistent case definition for asthma and identical study methodologies. This would allow cross country comparison of data and provide a benchmark for future studies.

Despite the magnitude of the disease, data on the epidemiology and disease burden of asthma in the Middle East region are scarce. Local observational studies investigating the current prevalence of asthma in adults have been conducted, but few studies provide prevalence estimates at a multinational level using a standardised methodology and the data is relatively out-dated as the majority of the studies were completed prior to 2010 . In Turkey, the published prevalence ranges from 2.11\% - 8.35\% $[9,11-15]$. In the United Arab Emirates (UAE) the reported prevalence ranges from $2.79 \%-8 \%[14,16,17]$ and in Saudi Arabia, a national household survey was carried out in 2013 which reported an asthma prevalence of 4.05\% [18]. In the North African countries, the most recent data are from the AIR Maghreb (AIRMAG) study carried out between 2008 and 2009 [19], which investigated asthma prevalence in Algeria, Morocco and Tunisia. Earlier data (2002-2003) is available from the WHS survey [14]. In these countries, the reported prevalence rates ranged from $2.79 \%$ to $3.89 \%$. In Egypt many studies on asthma have been performed in the paediatric age groups but very few addressed the adult population and were not representative of the whole country [20].

In some areas, there is limited regional information available. In addition, results from the existing studies rely on a variety of methodologies used to capture the information, the different population sources and variety of sampling methods, the different modes of interview, and the lack of a common case definition for asthma, and differing interpretation of symptoms in different countries all limit the ability to compare the data. Hence, there is a need to provide up to date information on the prevalence of asthma in Middle Eastern countries. To address this, we have conducted a large, cross-sectional, populationbased study as part of the SNAPSHOT program, using a standardised methodology in five countries in the region, to investigate the current prevalence of asthma in the adult population.

\section{Methods \\ The SNAPSHOT program}

SNAPSHOT is a cross-sectional, observational, populationbased program, comprising multiple studies, conducted in a random sample of the general population of five countries (Egypt, Kuwait, Saudi Arabia, Turkey, and the UAE). The objective of the SNAPSHOT program was to provide an omnibus approach to collect data simultaneously about multiple diseases using a standardised methodology. The program provides updated epidemiological data on the prevalence, burden of disease, quality of life and healthcare resource use related to four chronic diseases in the participating countries, namely: asthma, allergic rhinitis, bipolar disorder and benign prostatic hyperplasia (BPH). The selection of these diseases was based on the need to respond to emerging health technology assessment (HTA) requirements. The detailed study methodology is the subject of a separate manuscript [21].

The program was carried out by computer-assisted personal interviewing (CAPI) conducted over the telephone and the information collected via web-based electronic data capture. Interviews were proposed in Arabic, English or Turkish using translated validated questionnaires and conducted by trained staff of local specialised Contract Research Organisations (CROs); Omega (Turkey) for interviews in Turkey and Infomine Healthcare Research (Egypt) for interviews in the Arabicspeaking countries. Data management and analyses were performed by MS Health (Morocco).

\section{The SNAPSHOT sample}

The SNAPSHOT population was generated using a random stratified sampling method. Enrolment began in July 
2014. A target sample of 10,000 subjects from the adult general population of Turkey and Egypt and 15,000 for the Gulf cluster (comprised of Kuwait, Saudi Arabia and the UAE) was defined based on the demographic structure of the country in terms of age and gender, to enable the estimate of prevalence and disease burden with a satisfactory precision. In the Gulf cluster, the target sample size could not be reached despite extensive efforts to accelerate subject enrolment. Therefore, it was decided to stop recruitment in February 2016. The combined number of interviews conducted to date in Saudi Arabia, Kuwait and UAE showed that the program objectives could be achieved from a sample size perspective. The database was locked on 11th April 2016.

\section{Subject enrolment}

Telephone numbers (landline and mobile) were generated in blocks using an assisted random-digit dialling procedure. Each number was dialled up to fifteen times on different days and times including weekends and evenings until contact was established. After fifteen attempts, outcomes were categorised as contact, unattributed, out-of-service, fax, or unreachable. In order to optimise response rates, successive blocks of numbers were defined and the release of a new block could only occur once the previous block had been completed. This process was repeated until the target number for each country / cluster was achieved.

If telephone contact was established, the interviewer first assessed the eligibility of the telephone number (business numbers were ineligible). For eligible numbers, the interviewer determined the respondent's age, gender and region of residence. All subjects $\geq 18$ years of age who had been residing in the country for over 6 months were eligible, unless the pre-specified strata for age, gender and region was filled. If the subject was ineligible, this was documented and the phone call terminated. If the subject was eligible, the interview began. If the respondent agreed to continue the interview but asked to be called back later, up to ten attempts were made after which this was classified as a call-back failure and considered a refusal. Subject flow through the recruitment process is shown in Fig. 1. The overall response rate was $50.9 \%$. At a country level it varied by a factor of almost two, from $35.3 \%$ in Kuwait, $40.0 \%$ in UAE and $40.6 \%$ in Saudi Arabia to $58.9 \%$ and $67.4 \%$ in Turkey and Egypt respectively.

\section{Conduct of the interview}

Standardised general information was provided at the start of the interview, specifying that participation was voluntary, confidential and anonymous. Verbal consent to participate was collected by the interviewee and recorded in the CAPI system and the interviewee was then invited to respond to a first questionnaire, screening for the four diseases of interest and to document social and demographic characteristics, as well as the presence of co-morbidities. If the interviewee did not want to answer, the contact was considered as a refusal and the interview terminated. If a subject screened positive for at least one of the four diseases, a second disease-specific questionnaire was administered to collect additional information on burden of disease, disease management and healthcare resource utilisation. In cases where respondents fulfilled the screening criteria for more than

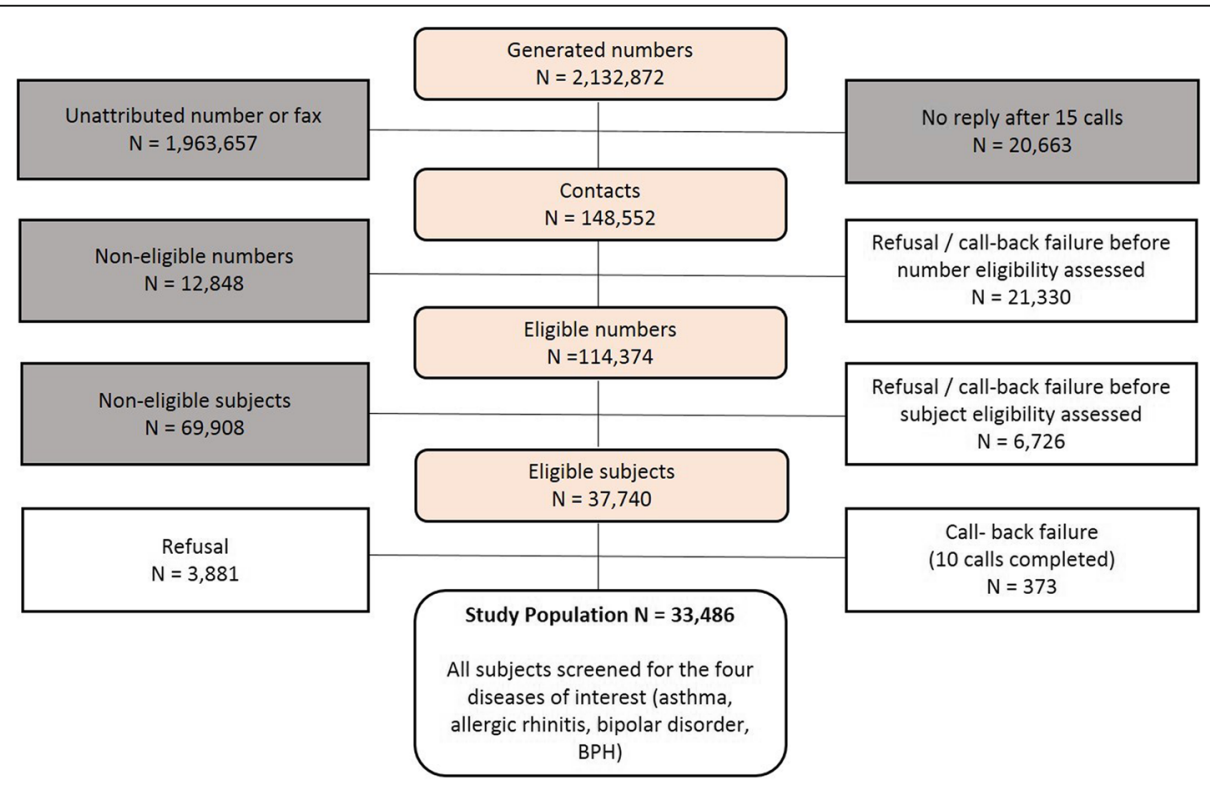

Fig. 1 Subject flow through the recruitment process. The grey boxes indicate excluded numbers or subjects, and the white boxes the groups of potentially eligible numbers or subjects taken into account in the calculation of the response rate 
one disease, they were randomised by the CAPI system to respond to only one of the disease-specific questionnaires, in order to limit the duration of the interview. For all subjects the interview ended with the EuroQoL five-dimension questionnaire (EQ-5D), a measure of health status which captures the impact of a disease on physical, mental, and social functioning [22, 23]. All questionnaires were used in validated English, Turkish or Arabic translations; the translated versions are available on request. The full interview was conducted in one telephone call.

\section{Case definition for asthma}

Subjects were considered to have asthma if they fulfilled the screening criteria shown in Table 1 , which were based on the criteria used in the global AIR studies [8]. A positive answer to any of the latter three questions (Q3-Q5) led to classification of the interviewee as a subject with asthma. It is important to note that the criteria were designed to collect information on the current prevalence (last 12 months) and not the lifetime prevalence of the disease.

\section{Data collected for this analysis}

This analysis focuses solely on asthma and aims to provide estimates of the current prevalence of asthma in the areas studied. Socio-demographic data were collected to describe the characteristics of the overall study population, including gender and age distribution, marital status, educational level, employment status, health system coverage, body mass index (BMI), the presence of comorbidities and smoking status. If a respondent was a current or former smoker, they were asked to provide the duration and extent of exposure. Additionally, the

Table 1 Screening Criteria for Asthma. A positive answer to any of the latter three questions (Q3-Q5) led to classification of the interviewee as a subject with asthma

\begin{tabular}{ll}
\hline Screening Criteria for Asthma & \\
\hline Q1 Have you been told by your doctor that you suffer from & $\square$ No \\
asthma? & $\square$ Yes \\
Q2 Have you had one of the following symptoms: wheezing, & $\square$ No \\
nocturnal coughing, chest tightness, or breathless ness in & $\square$ Yes \\
the last 12 months & \\
Q3. Have you had an asthma attack in the last 12 months? & $\square$ No \\
& $\square$ Yes \\
Q4. Have you used asthma medications in the last & $\square$ No \\
12 months? & $\square$ Yes \\
Q5. Have you used Ventolin or inhaled bronchodilators or & $\square$ No \\
short acting $\beta$ agonist in the last 12 months? & $\square$ Yes \\
If yes, what is the daily frequency of use? & $\square$ Once \\
& $\square$ \\
\hline
\end{tabular}

type and frequency of co-morbidities were investigated and risk factors related to asthma identified. As part of the screening questionnaire, subjects were also screened for allergic rhinitis using the Score for Allergic Rhinitis (SFAR) questionnaire [24] and asked about any family history of this disease to identify asthma subjects who had co-morbid allergic rhinitis or a family history of allergic rhinitis. All subjects were also asked to complete the EQ-5D-3L questionnaire to measure quality of life, a generic questionnaire to measure health status. The questionnaire consists of five dimensions (mobility, selfcare, usual activities, pain / discomfort, anxiety / depression) each of which can take one of three responses (no problems / moderate problems / extreme problems) and a visual analogue rating scale (EQ-VAS) [22]. Asthma prevalence data were collected using the case definition described and the prevalence by age, gender, country and region was assessed.

\section{Statistical analysis}

The data presented here are for the screening population of 33,486 subjects who accepted to participate in the study, completed all screening questionnaires and thus constituted the screening population. Prevalence was adjusted for age and gender by weighting each subject to take into account the actual structure of age and gender in the national population for each country [25]. This adjustment also took into account the additional weight given to men over the age of 50 which was necessary to enable the prevalence of BPH to be estimated accurately.

Data are presented as proportions and means with standard deviations (SD), or medians with interquartile ranges (IQR). 95\% confidence intervals (95\% CI) were calculated for binomial data. Associations between categorical variables were estimated using the $x^{2}$ test and the Cochran-Mantel-Haenszel test as appropriate. Two-sided tests were used in all cases and a probability threshold of 0.05 was considered significant. Multivariate regression analysis was performed to identify risk factors associated with asthma. In a first step, variables were evaluated independently in a univariate analysis. All variables with a $P$ value $<0.20[26]$ in the univariate analysis were entered into the multiple logistic regression analysis in which variables were retained in the model using a backward stepwise selection to determine the variables associated with an increased risk of asthma at the probability level of 0.05 . In addition, variables hypothesised to have clinical relevance but not found to be significant at 0.20 were maintained (e.g. age). A final multivariate analysis was conducted to generate odds ratios. Multivariate regression analysis was also performed to assess the relationship between co-morbidities and asthma independent of age, gender and country and the relationship between allergic rhinitis and asthma. All statistical 
analyses were performed using $\mathrm{SAS}^{\bullet}$ Version 9.4 (SAS, Cary, USA).

\section{Results Study sample}

A total of 33,486 subjects agreed to participate in the screening questionnaire and constituted the screening population. This population was distributed between Egypt $(10,014)$, Turkey $(10,000)$ and the Gulf cluster $(13,472)$. Overall, approximately $60 \%$ of respondents were men and $40 \%$ women (sex ratio: 1.41; 19,610 were men). The majority were aged between 18 and 35 (47.7\%; $n=15,959$ ). Just over half of the remaining respondents were between 35 and 50 years of age $(29.6 \% ; n=9921)$ and the rest were aged 50 or above $(22.7 \% ; n=7606)$. Selected demographics of the screening population are shown in Table 2. These data highlight that the majority of the screening population are non-smokers (65\%) and either overweight or obese (54\%).

\section{Current prevalence of asthma}

Of the subjects enrolled in the study 2124 fulfilled the case definition for asthma and were defined as the asthma population. Overall, the adjusted prevalence of asthma in the adult general population over 18 years of age in the countries studied was 6.4\% [95\% CI: 6.1-6.6\%]. This ranged from $4.4 \%$ in Turkey, to $6.7 \%$ in Egypt and $7.6 \%$ in the Gulf cluster (Table 3). After adjusting for age and gender there is little difference between the crude and adjusted prevalence. The adjusted prevalence by country in the Gulf cluster was 9.5\% [95\% CI: 8.1-10.9\%] in Kuwait, 4.9\% [95\% CI 4.2-6.6\%] in the UAE, and 8.3 [95\% CI 7.78.9\%] in Saudi Arabia.

The current prevalence of asthma was significantly higher in women compared to men across all countries and the cluster of countries studied $(p<0.0001)$. Age is also an important factor; the current prevalence of asthma increased significantly with age $(p<0.0001)$. These results are presented in Table 3. Further analysis of the age and gender split by country showed that for each country or cluster of countries the observed prevalence of asthma was higher in women than in men across every age group studied (data not shown).

Current asthma prevalence was also investigated by region across the countries studied and these results are shown in Fig. 2. In Egypt, the highest prevalence was documented in Greater Cairo / North Egypt, and the Canal/other region followed by Upper Egypt $(p<0.0096)$. In the Gulf cluster, there was a significant difference in prevalence across the countries and regions studied $(p<0.0001)$. In Saudi Arabia, the central region reported a prevalence of $10.5 \%$ which is significantly higher than the coastal regions in the east and west which reported a prevalence of $6.5 \%$ and $7.0 \%$ respectively. The prevalence in
Kuwait was comparatively high compared to most other regions in the Gulf cluster although the reported prevalence in western Kuwait (10.6\%) was in line with that seen in central Saudi Arabia. The prevalence in the UAE was slightly lower than the rest of the Gulf cluster but consistent across the country. In Turkey, there was no significant difference in prevalence across the regions studied $(p=0.36)$.

\section{Asthma and smoking status}

There was no statistical difference $(p=0.99)$ in the percentage of respondents who smoked between the asthma population (66.5\%) and the non-asthma population (66.3\%). Among current or former smokers, there was no statistical difference $(p=0.08)$ in the number of pack-years for the asthma population $(18.9 \pm 23.0)$ compared to the nonasthma population $(17.3 \pm 20.4)$.

\section{Risk factors for asthma}

The following variables were tested in a univariate analysis looking at potential risk factors for asthma: marital status, employment status, BMI, smoking status, co-morbidities yes/no, age, gender and country (Egypt, Kuwait, Saudi Arabia, Turkey, UAE). Those variables found to be significant at 0.2 were entered into the multivariate analysis. The variable smoking status was not found to be significant. However, to further explore a potential association between smoking and asthma this variable was maintained in the multivariate analysis. The results of a multivariate regression analysis show a significant association between living in Kuwait or Saudi Arabia and having asthma (odds ratio (OR) 1.8 and 1.4 respectively) compared to living in Egypt $(p<0.0001)$. In addition, a significant association $(p<0.0001)$ was observed between asthma and obesity (OR 1.5), smoking (OR 1.4), and the presence of co-morbidities (OR 3.1). These results are shown in Fig. 3.

\section{History of co-morbidities and the impact on the asthma population}

The number of subjects that reported suffering from a chronic health condition was significantly higher $(p<0.0001)$ in the asthma population $(38.4 \%)$ compared to the non-asthma population (15.4\%). The following variables were tested in a univariate analysis looking at the relationship between co-morbidities and asthma: cardiovascular disease, nervous disease, neurological disease, respiratory disease, gastrointestinal disease, renal disease, rheumatological disease, endocrine disease (diabetes), malignancy disease, immunological disease and adjusted for age, gender and country (Egypt, Kuwait, Saudi Arabia, Turkey, UAE). Those found to be significant at 0.20 were entered into a multivariate analysis to investigate the relationship 
Table 2 Demographics of the screening population

\begin{tabular}{|c|c|c|c|c|}
\hline \multirow[t]{2}{*}{ Demographic } & \multirow[t]{2}{*}{ Criteria } & \multirow{2}{*}{$\begin{array}{l}\text { Egypt } \\
N=10,014\end{array}$} & \multirow{2}{*}{$\begin{array}{l}\text { Gulf cluster } \\
N=13,472\end{array}$} & \multirow{2}{*}{$\begin{array}{l}\text { Turkey } \\
N=10,000\end{array}$} \\
\hline & & & & \\
\hline \multirow[t]{3}{*}{ Gender n (\%) } & Count & 10,014 & 13,472 & 10,000 \\
\hline & Men & $5747(57.4)$ & $8524(63.3)$ & $5339(53.4)$ \\
\hline & Women & $4267(42.6)$ & $4948(36.7)$ & $4661(46.6)$ \\
\hline \multirow[t]{4}{*}{ Age $n(\%)$} & Count & 10,014 & 13,472 & 10,000 \\
\hline & 18-34 years & $4978(49.7)$ & 7055 (52.4) & 3926 (39.3) \\
\hline & $35-49$ years & $2453(24.5)$ & $4745(35.2)$ & $2723(27.2)$ \\
\hline & $\geq 50$ years & $2583(25.8)$ & $1672(12.4)$ & $3351(33.5)$ \\
\hline \multirow[t]{6}{*}{ Marital Status n (\%) } & Count & 9814 & 13,013 & 9522 \\
\hline & Married & $7357(75.0)$ & $9000(69.2)$ & $7054(74.1)$ \\
\hline & Living as unmarried couple & $3(0.03)$ & $4(0.03)$ & $6(0.06)$ \\
\hline & Separated/divorced & $160(1.6)$ & $325(2.5)$ & $130(1.4)$ \\
\hline & Widowed & $362(3.7)$ & $206(0.02)$ & $390(4.1)$ \\
\hline & Single/never married & $1932(19.7)$ & $3478(26.7)$ & $1942(20.4)$ \\
\hline \multirow[t]{8}{*}{ Education level $n(\%)$} & Count & 9755 & 12,877 & 9079 \\
\hline & No high school & $2767(28.4)$ & 1789 (13.9) & $5245(57.8)$ \\
\hline & Some high school & $236(2.4)$ & $283(1.2)$ & $156(1.7)$ \\
\hline & High school graduate & $2291(23.5)$ & $3501(27.2)$ & $1842(20.3)$ \\
\hline & Technical post-secondary & $1386(14.2)$ & $834(6.5)$ & $306(3.4)$ \\
\hline & Some college & $434(4.5)$ & $757(5.9)$ & $430(4.8)$ \\
\hline & College graduate & $2267(23.2)$ & $4837(37.5)$ & $1040(11.5)$ \\
\hline & Post graduate degree & $374(3.8)$ & $876(6.8)$ & $60(0.7)$ \\
\hline \multirow[t]{7}{*}{ Employment Status n (\%) } & Count & 9735 & 12,834 & 9721 \\
\hline & Employed (full or part time) & $5592(57.4)$ & $8732(68.0)$ & $4299(44.2)$ \\
\hline & Unemployed & $447(4.6)$ & $584(4.6)$ & $1243(12.8)$ \\
\hline & Retired and not working & $579(6.0)$ & $291(2.3)$ & $1462(15.0)$ \\
\hline & Student & $524(5.4)$ & $738(0.06)$ & $340(3.5)$ \\
\hline & Homemaker & $2545(26.1)$ & 2466 (19.2) & $2370(24.4)$ \\
\hline & Disabled or too ill to work & $48(0.5)$ & $23(0.2)$ & $7(0.07)$ \\
\hline \multirow[t]{5}{*}{ Yearly Household Income $n$ (\%) } & Count & 9.596 & 12,555 & 9125 \\
\hline & $<$ minimum wage & $3465(36.1)$ & $1616(12.9)$ & $1427(15.6)$ \\
\hline & Minimum wage & $4110(42.8)$ & 8917 (71.0) & $3023(33.1)$ \\
\hline & $2 \times$ minimum wage & $1277(13.3)$ & $1243(9.9)$ & $4276(46.9)$ \\
\hline & $>2$ times minimum wage & $744(7.8)$ & $779(6.2)$ & $399(4.4)$ \\
\hline \multirow[t]{3}{*}{ Smoking n (\%) } & Count & 9814 & 13,014 & 9784 \\
\hline & Non-smoker & $6513(66.4)$ & 9176 (70.5) & $5942(60.7)$ \\
\hline & Current/former smoker & 3301 (33.6) & 3838 (29.5) & $3842(39.3)$ \\
\hline \multirow[t]{5}{*}{ BMI $n(\%)$} & Count & 9338 & 12,156 & 9028 \\
\hline & Underweight & $230(2.5)$ & 469 (3.9) & $271(3.0)$ \\
\hline & Normal weight & 3060 (32.8) & 4605 (37.9) & $3826(42.4)$ \\
\hline & Overweight & 3253 (34.8) & 4333 (35.6) & $3299(36.5)$ \\
\hline & Obese & 2795 (29.9) & 2749 (22.6) & $1632(18.1)$ \\
\hline
\end{tabular}


Table 3 Current prevalence of asthma

\begin{tabular}{|c|c|c|c|c|}
\hline \multirow[t]{2}{*}{ Variable } & & \multirow{2}{*}{$\begin{array}{l}\text { Egypt } \\
N=10,014\end{array}$} & \multirow{2}{*}{$\begin{array}{l}\text { Gulf cluster } \\
\mathrm{N}=13,472\end{array}$} & \multirow{2}{*}{$\begin{array}{l}\text { Turkey } \\
\mathrm{N}=10,000\end{array}$} \\
\hline & & & & \\
\hline Number of Cases & & 676 & 1003 & 445 \\
\hline Crude Prevalence (\%) & & 6.8 & 7.5 & 4.5 \\
\hline Adjusted Prevalence (\% & & 6.7 & 7.6 & 4.4 \\
\hline Adjusted 95\% Cl & & {$[6.2-7.2]$} & {$[7.1-8]$} & {$[4.0-4.8]$} \\
\hline \multirow[t]{3}{*}{ Gender (\%) $[95 \% \mathrm{Cl}]$} & Men & $5.5[4.9-6.1]$ & $6.2[5.7-6.7]$ & $2.9[2.4-3.3]$ \\
\hline & Women & $8.4[7.6-9.3]$ & $9.6[8.7-10.4]$ & $6.3[5.6-7]$ \\
\hline & $P$ value (CMH test) & $p<0.0001$ & & \\
\hline \multirow[t]{4}{*}{ Age (\%) $[95 \% \mathrm{Cl}]$} & $18-34$ & $5.5[4.8-6.1]$ & $7.0[6.4-7.6]$ & $2.6[2.1-3.1]$ \\
\hline & $35-49$ & $7.7[6.7-8.8]$ & $7.7[7-8.5]$ & $4.0[3.3-4.8]$ \\
\hline & $\geq 50$ & $8.3[7.3-9.4]$ & $8.7[7.3-10.0]$ & $7.0[6.1-7.8]$ \\
\hline & $P$ value (CMH test) & $p<0.0001$ & & \\
\hline
\end{tabular}

Current prevalence (\%) of asthma by country and cluster, adjusted by age and gender as required. $\mathrm{CMH}$ : Cochran $\mathrm{Mantel}-\mathrm{Haenszel} ; 95 \% \mathrm{Cl}=95 \%$

Confidence Interval

between each of the co-morbidities and the risk of asthma, independent of age, gender and country. The results show that the co-morbidity with the highest impact is respiratory disease (OR 44.6). Detailed investigation into the conditions classified under the co-morbidity 'respiratory disease' revealed that this refers primarily to chronic obstructive pulmonary disease (COPD). This was followed by neurological disease (OR 2.5), cardiovascular disease (OR 2.1), gastrointestinal disease (OR 1.8) and nervous disease (OR 1.5). These results are presented in Fig. 4.

A large number of subjects with asthma (482) were found to have co-morbid allergic rhinitis and 271 subjects reported having a family history of the disease, although they did not have allergic rhinitis themselves. A multivariate regression analysis looking specifically at the relationship between allergic rhinitis and asthma, adjusted for age, gender and country showed a strong association $(p<0.0001)$ between the two diseases (OR 6.4; 95\% CI 5.7-7.2). In case of a family history of allergic rhinitis in subjects without allergic rhinitis themselves a weaker association with asthma was observed (OR 1.7; 95\% CI 1.0-3.0).

\section{Impact of asthma on quality of life}

Overall, subjects with asthma reported a significantly lower $(\mathrm{p}<0.0001)$ mean EQ-5D-3L utility score $(0.74 \pm$ $0.34)$ than the general population $(0.90 \pm 0.21)$. This relationship was observed for all participating countries or cluster of countries. A similar observation was made for the mean EQ-VAS scores $(68.2 \pm 22.9$ in subjects with asthma; $78.1 \pm 17.5$ in the general population $\mathrm{p}<0.0001$ ). The overall impact and the country-level results are presented in Fig. 5.

\section{Discussion}

Omnibus programs such as SNAPSHOT represent a powerful approach for generating standardised epidemiological data on important health indicators such as prevalence. In particular, the use of a common methodology to collect the data enables pertinent comparisons to be made between countries and between diseases. Although setting up multidimensional studies such as this on a large scale is time- and resource- consuming, once the data acquisition system has been validated it would be relatively straightforward to implement the same program in further groups of countries.

In this program the overall response rate was $50.9 \%$. The SNAPSHOT program was conducted in a random selection of the general population using telephone interview. In this context, a high level of refusal is common since people often do no do not respond to such calls requesting information, from which they receive no immediate benefit. However, the combination of refusals and call-back failures, and the inclusion of subjects prior to confirmation of eligibility criteria in the response rate calculation, reflects a conservative approach. If we assume that the distribution of eligible/non-eligible subjects is identical for respondents and non-respondents, then the response rate could be estimated as $56.5 \%$. Further exclusion of call-back failures from the calculation would have yielded a response rate of $70.6 \%$. If this nonconservative response rate is used then the response rate for the SNAPSHOT program is within the range of that observed in AIR studies elsewhere, such as Europe (80\%) [27], and the Maghreb [19].

The primary objective of this study was to estimate the prevalence of asthma in five countries in the Middle East (Egypt, Turkey Kuwait, Saudi Arabia, and the UAE). 


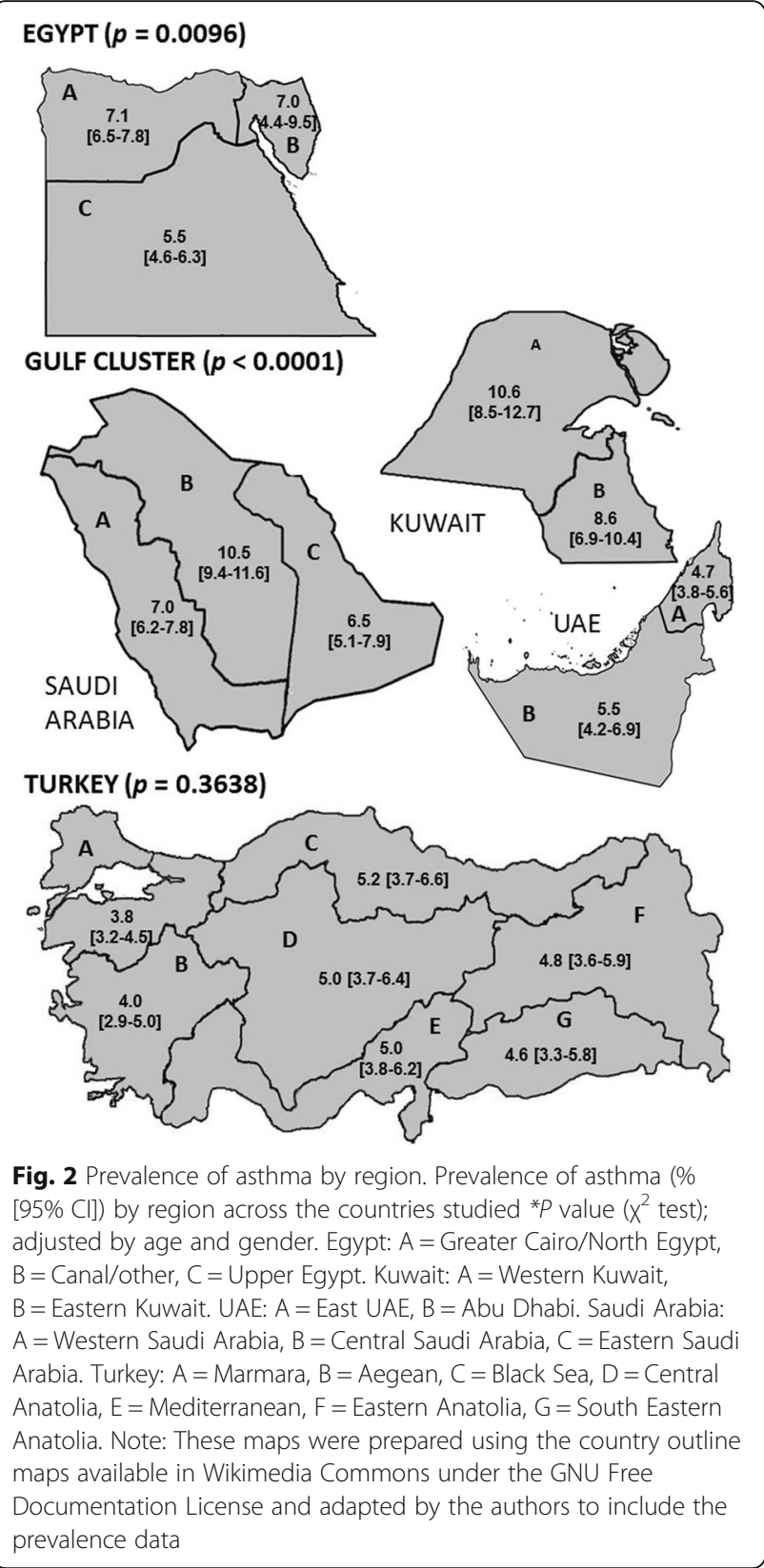

The overall current prevalence of asthma in the adult general population over 18 years of age in these countries was $6.4 \%$. This ranged from $4.4 \%$ in Turkey, to 6 . $7 \%$ in Egypt and $7.6 \%$ in the Gulf Cluster.

The global AIR studies have been conducted in many countries, and although these studies use the same questionnaire, a very broad range of prevalence estimates has been observed in the different studies conducted (ranging from $1 \%$ in Ecuador to $15 \%$ in Singapore) [28]. Comparison of the reported prevalence of asthma in these Middle Eastern countries with data obtained through the AIR studies demonstrates that the prevalence of asthma in the participating countries is low compared with the United Kingdom but slightly higher than some other European countries such as Germany [27], and considerably higher than countries in Asia such as China and Malaysia [29].

Comparison with published epidemiological data on the prevalence of asthma in the Middle East is difficult, since the criteria used to define asthma vary between studies and the methodologies are not consistent. For example, the studies use different case definitions for asthma; different populations, different modes of interview; or different age cut-offs for inclusion. This has led to a range of prevalence estimates being reported. One of the objectives of the SNAPSHOT program was to use a consistent case definition and study methodology across all countries included, to overcome this issue and enable comparison of the results.

To gain a better understanding of previously published asthma prevalence data in the region, a literature review was performed. This review focused on general population studies which investigated asthma prevalence in the Middle East and North Africa region. In line with the parameters of the SNAPSHOT study, the search was limited to population-based, observational studies that focused on the current prevalence of asthma in adults. The search was restricted to articles that were in English, available via PubMed, and were published between January 1st 2000 and December 31st 2015 [9, 11-19]. The findings, together with the results from the SNAPSHOT study (denoted by a red star), are depicted in Fig. 6. The reported prevalence of asthma in Turkey and the UAE is within the range of the published literature and there are no published studies that fulfil the specified inclusion criteria in Egypt and Kuwait. A higher prevalence of asthma was observed in Saudi Arabia compared to the previously published data. This could be due to methodological differences between the studies, (the interviews in the previous study had been conducted face-to-face which tends to yield lower prevalence estimates than telephone or postal questionnaires), although a real increase in prevalence over time cannot be excluded, perhaps linked to the increasing urbanisation of the country [30].

Whilst the prevalence of asthma in Turkey reported here is within the range reported by comparable studies in the country, the prevalence reported in Turkey was generally lower than in Egypt or the Gulf cluster, the reported prevalence in the 18-34 age group was particularly low at $2.6 \%$. There are few published studies that have investigated asthma prevalence by age in Turkey, and none using equivalent methodology to SNAPSHOT. However, a study carried out in the city of Samsun reported the prevalence by asthma diagnosis as $1.0 \%$ in the $15-29$ age group and $2.6 \%$ in the $30-49$ age group, and by use of medication as $1.0 \%$ and $1.8 \%$ in these 


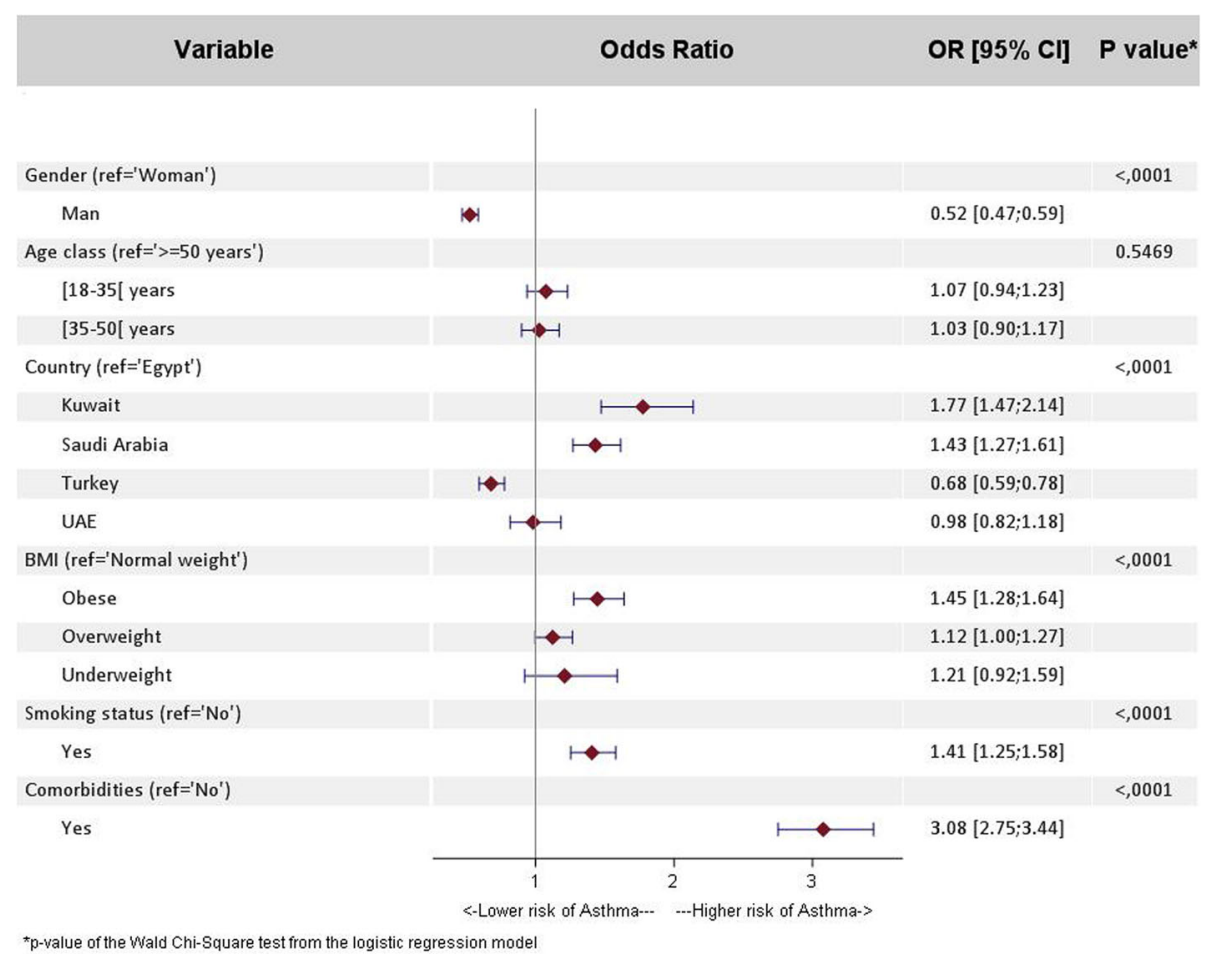

Fig. 3 Multivariate regression analysis investigating the risk factors for asthma: Asthma population (1931 subjects) versus non-asthma population (28,586 subjects); OR [95\% Cl] = odds ratio [95\% Confidence Interval]. The results presented are adjusted for age (18-34,35-49, $\geq 50$ years), gender and country (Egypt, Kuwait, Saudi Arabia, Turkey, UAE)

respective age groups [31]. This is in line with the findings presented here.

It has been documented that the prevalence of allergic disease is generally higher in urban compared to rural areas [32]. Consistent this with theory, the United Nations (UN) 2014 World Urbanisation report indicates that the Gulf countries that participated in this study have a higher urban population percentage than Turkey and Egypt, and this cluster reports the highest prevalence of asthma. However, The UN report estimates $43 \%$ of the Egyptian population are urban compared to $73 \%$ of the Turkish population, yet the reported prevalence of asthma in this study is higher in Egypt compared to Turkey [33]. Data from our study also describes regional variations in prevalence that cannot be explained solely by urbanisation. For example, whilst the regional asthma prevalence reported in Kuwait could correlate with the presence of increased urban extents as defined in the Global Rural-Urban Mapping Project (GRUMP) [34], this is not the case for Saudi Arabia, where the highest urban extents are reported in the western region [35], yet the highest asthma prevalence in this study was reported in central Saudi Arabia. The variations in prevalence between countries and regions reported in the SNAPSHOT study could be influenced by population density and urbanisation. However, these may not be the only factors involved; for example, elements such as air pollution, climate exposure and allergens could play a role.

Many studies have consistently shown a higher prevalence of asthma in women during adulthood [36, 37]. Consistent with this, the current prevalence of asthma reported in SNAPSHOT was higher among women compared to men, a trend observed across all the countries studied. Multiple hypotheses have been put forward to explain this difference. For example, it has been reported that the prevalence of asthma increases significantly after puberty for women and female sex hormones may play a role [38]. However, to date no single explanation can fully explain the differences observed.

Smoking is considered a major risk factor for several diseases, one of which is COPD [39], and COPD often presents with similar symptoms to asthma. This can make a differential diagnosis of asthma more challenging, particularly in general population surveys like SNAPSHOT with lay interviewers and no case ascertainment by a physician. There was no significant difference between the numbers of smokers in the asthma population compared to the non-asthma population, suggesting little or no contamination of this population with COPD patients who have been wrongly classified as subjects with asthma, and supporting the case definition of asthma used in the SNAPSHOT study. Interestingly, despite the fact that 


\begin{tabular}{|c|c|c|c|c|c|}
\hline Variable & No Asthma & Asthma & Odds Ratio & OR $[95 \% \mathrm{Cl}]$ & P-value* \\
\hline Cardiovascular disease (ref='No') & & & & & $<0.0001$ \\
\hline Yes & $2457(7.83 \%)$ & $401(18.88 \%)$ & $\mapsto-1$ & $2.11[1.84 ; 2.43]$ & \\
\hline Nervous disease (ref='No') & & & & & 0.0161 \\
\hline Yes & $346(1.1 \%)$ & $47(2.21 \%)$ & $\mapsto$ & $1.53[1.08 ; 2.17]$ & \\
\hline Neurological disease (ref='No') & & & & & 0.001 \\
\hline Yes & $84(0.27 \%)$ & $20(0.94 \%)$ & $\longmapsto$ & $2.53[1.46 ; 4.40]$ & \\
\hline Respiratory disease (ref='No') & & & & & $<0.0001$ \\
\hline Yes & $105(0.33 \%)$ & $277(13.04 \%)$ & & $44.6[35.2 ; 56.6]$ & \\
\hline Gastrointestinal disease (ref='No') & & & & & $<0.0001$ \\
\hline Yes & $472(1.51 \%)$ & $75(3.53 \%)$ & $\longmapsto$ & $1.78[1.34 ; 2.35]$ & \\
\hline Diabetes (ref='No') & & & & & 0.9901 \\
\hline Yes & $192(9.04 \%)$ & $1740(5.55 \%)$ & $10-1$ & $1.00[0.84 ; 1.20]$ & \\
\hline \multicolumn{6}{|c|}{${ }^{*} p$-value of the Wald Chi-Square test from the logistic regression model } \\
\hline \multicolumn{6}{|c|}{$\begin{array}{l}\text { Fig. } 4 \text { Multivariate regression analysis investigating the impact of co-morbidities on the risk of asthma. Asthma population (2124 subjects) versus non- } \\
\text { asthma population ( } 31,362 \text { subjects); OR [95\% Cl] = Odds Ratio [95\% Confidence Interval]. The results presented are adjusted for age (18-34,35-49, } \geq 50 \text { years), } \\
\text { gender and country (Egypt, Kuwait, Saudi Arabia, Turkey, UAE) }\end{array}$} \\
\hline
\end{tabular}

there was no difference in the prevalence of asthma between smokers and non-smokers in this study, smoking was identified as a risk factor for asthma. One factor contributing to this could be that that the prevalence of smoking in the Middle East and North Africa is higher in men, as reported in the BREATHE study [40], whereas the prevalence of asthma is higher in women as reported here.
This study shows an association between certain comorbidities and asthma, particularly allergic rhinitis (OR 6.4). The association between allergic rhinitis and asthma is supported in the literature [41]. The World Health organisation (WHO), through the Allergic Rhinitis and its Impact on Asthma (ARIA) program, has examined the impact of allergic rhinitis on asthma and
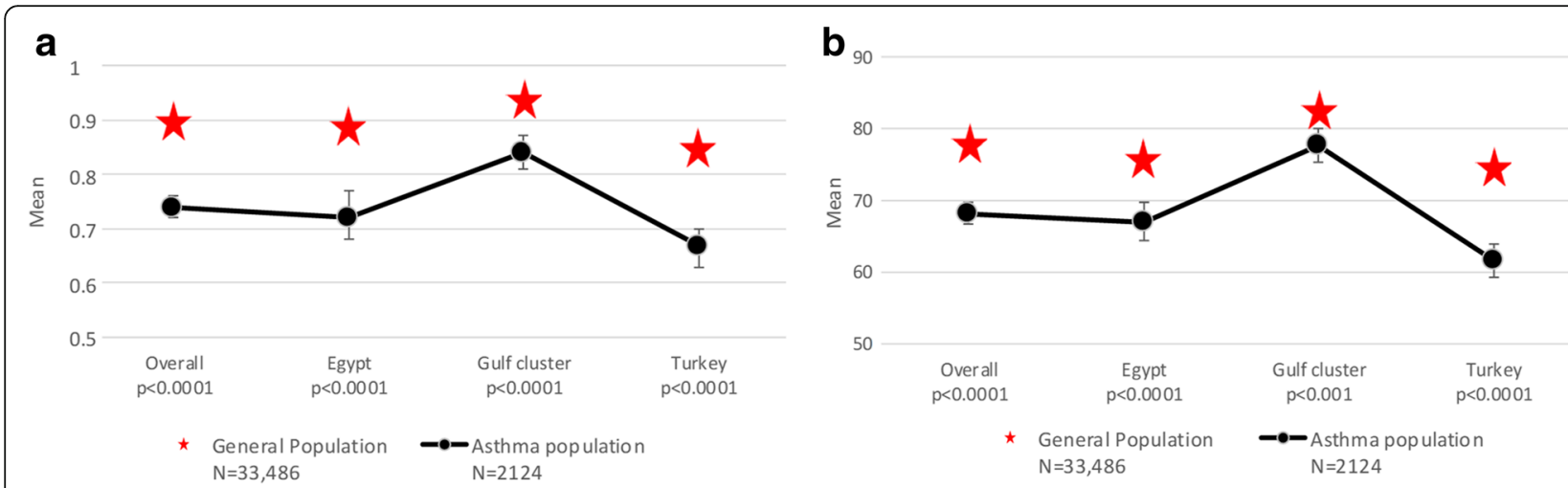

Fig. 5 Impact of asthma on quality of life. Quality of life was assessed using the three level EuroQol five-dimension questionnaire (EQ-5D-3L). Comparison of the EQ-5D-3L utility values (a) and EQ-VAS scores (b) between the asthma population and general population by country or cluster are shown. $\mathbf{a}$ For the asthma population $(n=2124)$ the data represent the mean EQ-5D-3L utility value with the $95 \% \mathrm{Cl}$. For the general population $(N=33,486)$, the mean EQ-5D-3L utility value is presented. $\mathbf{b}$ For the asthma population $(n=2124)$ the data represent the mean EQ-VAS score with the $95 \% \mathrm{Cl}$. For the general population $(n=33,486)$, the mean EQ-VAS score is presented 


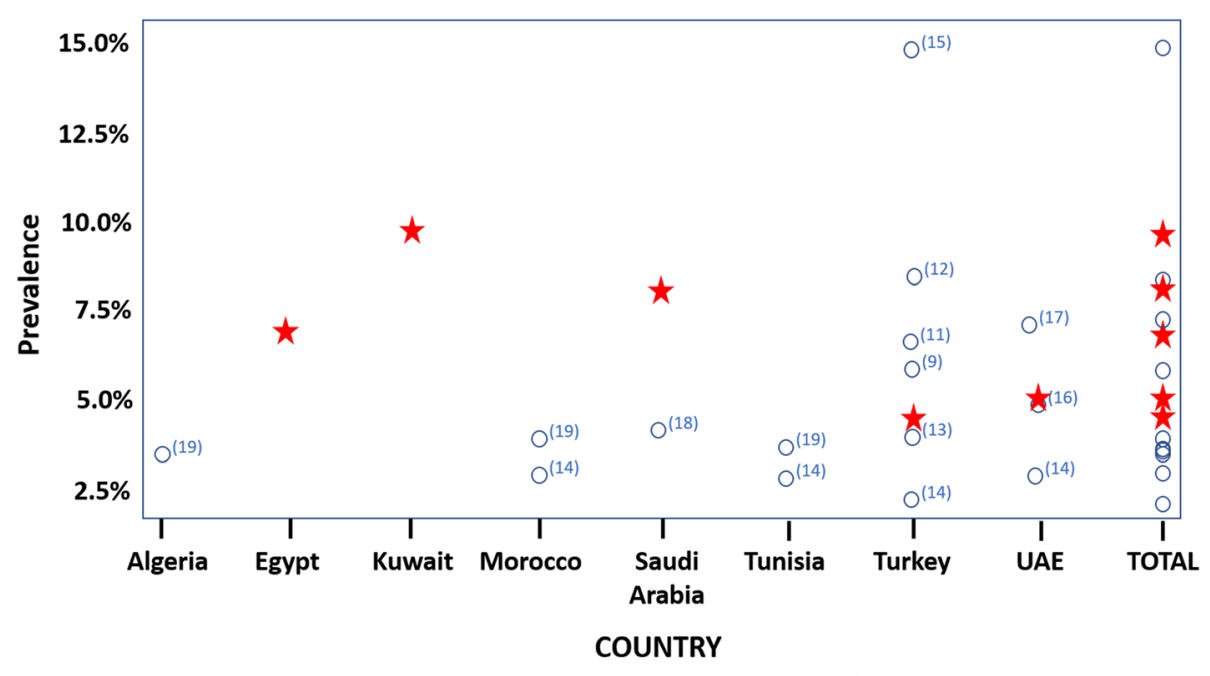

Publications $\star$ SNAPSHOT

Fig. 6 Asthma prevalence in the Middle East. Prevalence of asthma as reported by SNAPSHOT and earlier studies in the Middle East and North Africa region. The inclusion criteria for the literature review were: article published between January 2000 and December 2015 , population-based observational studies investigating the current prevalence of asthma in adults. The red star denotes the prevalence findings from the SNAPSHOT study. Note: two Turkish studies $[9,11]$ were carried out in urban centres only and were not national studies

concluded that both allergic and non-allergic rhinitis should be considered risk factors for asthma [42].

Overall, 54\% of the screening population and $67.5 \%$ of the asthma population are overweight or obese. This is high compared to the global estimate from the WHO in 2014 which stated that $39 \%$ of adults aged 18 years and over were overweight and $13 \%$ of those were obese [43]. However, data from the 2013 Global Burden of Disease study demonstrates a higher prevalence of obesity in the MENA region compared to the global average [44]. An association between obesity and asthma has previously been reported; a meta-analysis of prospective epidemiological studies reported that those overweight were $38 \%$ more likely to develop asthma, rising to $92 \%$ of those who were obese [45]. Given the high incidence of obesity in the screening population the impact of cardiovascular disease is not unexpected since obesity predisposes subjects to cardiovascular disease. However, cardiovascular disease has also been linked to asthma independently. For example, a cohort study carried out in Northern California reported an association between asthma and increased risk of cardiovascular disease in women [46]; a large cross-sectional population-based study carried out in Adelaide, Australia also showed an association between asthma and cardiovascular disease independent of $\mathrm{BMI}$, in a representative population sample aged 18 years and above [47]. An association between gastrointestinal disease and asthma was also reported in the SNAPSHOT study. Again, this could be linked to the high levels of obesity in the screening population and associated predisposition to gastro-oesophageal reflux disease
(GERD). Indeed, there are numerous studies demonstrating an association between asthma and GERD. One such study has shown an independent association of GERD with poorly controlled asthma [48].

In addition to the co-morbidities mentioned above a significant correlation was also observed for nervous and neurological disease. Previously published studies have documented an association between asthma and diseases of the nervous system such as cerebrovascular disease. For example, the Atherosclerosis Risk in Communities (ARIC) study reported an association between asthma and stroke. Interestingly however, this study did not find an association between asthma and cardiovascular disease [49]. Neurological diseases such as dementia have also been previously linked to asthma. For example, a retrospective cohort study carried out in Taiwan reported an increased risk of developing dementia for those people with asthma compared to without asthma within a follow up period of 11 years [50]. The high levels of co-morbidities identified in the asthma population indicate that physicians need to check for comorbidities as part of routine care and ensure they are managed correctly in all asthma patients as these conditions may influence asthma control.

Asthma is a condition that is known to have a negative impact on quality of life for those that suffer from the disease. Several disease specific questionnaires have been developed to assess the quality of life of patients with respiratory disease [51] and specifically asthma [52-56]. Both specific and generic quality of life measures $[22,57]$ have been used in a clinical setting to monitor the quality 
of life of asthma patients, and have demonstrated that asthma impairs quality of life with a more pronounced impact during exacerbations and in uncontrolled disease [58, 59]. However, general population studies investigating the effects of asthma on quality of life are scarce. The EQ-5D questionnaire is a widely used generic measure of healthrelated quality of life and is not specific to a particular disease, thus enabling comparisons between different disease areas. In addition, it is a brief, simple measure for patients to understand over the telephone in a general population setting. Previous studies with this questionnaire have demonstrated an impairment of quality of life in patients with respiratory disease [60]. The results of the SNAPSHOT study indicate that, across all countries studied, subjects with asthma suffer significant impairment in their quality of life. Whilst this observation is expected, it is the first time it has been shown in these countries on such a large scale in a general population setting.

The study has several strengths. It is a cross sectional, population-based study with a large sample size using consistent methodology across all countries, providing a standardised measure of prevalence in the Middle East. In addition, the case definition of asthma used is based on the global AIR surveys, and quality of life has been assessed using the EQ-5D questionnaire, which have been validated and used widely, enabling comparison with data collected elsewhere.

As with all studies, limitations do exist. These include the fact that the survey was telephone based, which could introduce a sampling bias if certain groups do not have access to a telephone, such as those in more remote, rural areas. However, the emergence of mobile telephones means that the majority of households in these countries have access to a telephone, and the SNAPSHOT program included both mobile and fixed landline telephone numbers. Another limitation was that the survey was conducted by trained lay interviewers; therefore, the diagnosis of asthma or other reported co-morbidities was not confirmed by a physician. In addition, reporting of a physician diagnosis of asthma was not one of the inclusion criteria for a positive screen. It is well-known that access to healthcare infrastructure and primary care is lower in the Middle East compared to Europe. Therefore, if the definition of asthma had been restricted to those subjects who had a confirmed asthma diagnosis by a physician, it would have excluded many subjects with undiagnosed asthma, as these subjects might experience issues around access to healthcare. The proportion of people with undiagnosed asthma is thought to be higher in this region compared to Europe. However, as part of the screening questionnaire, subjects were asked whether they had been told by a physician that they had asthma, and of the 2124 subjects with asthma included in the SNAPSHOT program, $70.2 \%$ $(n=1490)$ had a confirmed asthma diagnosis, validating the study findings based on the screening criteria used. As is the case for all studies that require participants to recall data, there is a risk of inaccuracy in the data collected. However, this is minimised by setting the inclusion criteria for the asthma population based on exacerbations and treatments over the last 12 months as opposed to simple symptom reporting.

\section{Conclusion}

This study provides an updated prevalence estimate for asthma within the adult general population of five countries in the Middle East region, using an identical methodology across all countries studied. The reported prevalence estimates suggest that the Middle East is a low/medium prevalence area compared to other regions in the world. Prevalence is higher among adult women than men and increases with age. A positive correlation was observed for co-morbidities such as allergic rhinitis. In addition, asthma was shown to have a negative impact on quality of life; the first time this has been shown in these countries through a large scale general population based study. The lack of reliable recent data on the prevalence and burden of disease is a major obstacle to the implementation of effective public health strategies for disease prevention and management. The results from this study can contribute to informed decision making when setting priorities public health policy and strategy to manage asthma in these countries.

\section{Abbreviations}

AIR: Asthma insights and reality; AIRMAG: Asthma insights and reality Maghreb; ARIA: Allergic rhinitis and its impact on asthma; ARIC: Atherosclerosis risk in communities; BMI: Body mass index; $\mathrm{BPH}$ : Benign prostatic hyperplasia; CAPI: Computer-assisted personal interviewing; Cl: Confidence interval; COPD: Chronic obstructive pulmonary disease; CRO: Contract research organisation; ECRHS: European community respiratory health survey; EQ5D: EuroQoL five dimension questionnaire; EQ-5D-3 L: 3 level EQ-5D questionnaire; EQ-VAS: EuroQol visual analogue scale; GA2LEN: Global allergy and asthma network of excellence; GEP: Good epidemiological practice; GERD: Gastro-oesophageal reflux disease; GRUMP: Global rural-urban mapping project; HTA: Health technology assessment; IQR: Inter quartile range; ISAAC: International study of asthma and allergies in childhood; OR: Odds ratio; SD: Standard deviation; SFAR: Score for allergic rhinitis; SFDA: Saudi food and drug authority; UAE: United Arab Emirates; UN: United Nations; WHO: World health organisation; WHS: World health survey

\section{Acknowledgements}

Editorial support in the form of manuscript development, collating of author comments, copy editing and referencing was provided by Sarah Osei-Ntem, an employee of Glaxo SmithKline (GSK). Data analysis input was provided by Leyla Depret-Bixio, a former employee of GSK.

The authors also wish to express their appreciation for the contributions of Ahmed Abu al Faraj*, Tamer Elfishawy, Hany Gamil*, Ridwaan Jhetam*, Saeed Noibi, Selda Özdemir*, Candice Pinto*, Nauman Rashid, Samer Talaat El

Falaky, Indira Umareddy* (GSK), Sophie Abadie, Salaheddine El Khadiri, Maria José Lopez (MS Health), and the participating Contract Research

Organisations (Infomine Research Middle East, Omega CRO) in different stages of the SNAPSHOT study.

*Formerly employed at GSK. 


\section{Funding}

Funding for this study was provided by GSK (GSK study number 201291, GSK study title: SNAPSHOT).

\section{Availability of data and materials}

Editors can seek information from the corresponding author regarding whether anonymised patient level data can be made available.

\section{Authors' contributions}

$A E H, F A$, and LT conceptualised the study. AEH, FA, LT, AD, HT*, OA, DM, $\mathrm{MAB}$ and $\mathrm{BM}$ contributed to the study design and interpretation of results, AL contributed to data collection and analysis. All authors contributed to and provided approval for the submitted manuscript.

\section{Ethics approval and consent to participate}

The study followed guidelines for good epidemiological practice (GEP) and pertinent local rules and regulations for each participating country. The protocol and amendments were submitted to the appropriate independent ethics committee in each country for approval. The following ethics committees approved the SNAPSHOT program: In Egypt, the Ministry of Health and Population, Central Directorate for Research and Health Development; In Kuwait, the Kuwait University Health Sciences Centre Ethical Committee; in Turkey, the Ankara University Medical Faculty Ethics Committee; and in the UAE, the Ethics and Research Committee of the University of Sharjah. In Saudi Arabia, no ethics approval was required, since SNAPSHOT was an epidemiological, cross sectional, population based study and as such is out of scope of the Saudi Food and Drug Authority (SFDA) approval and/or notification. The protocol specified that oral consent to participate in the study was required. At the start of the telephone call, subjects were asked to provide their consent to participate verbally, and this information was recorded in the CAPI system by the interviewee. Participants taking part in the study did not receive any financial compensation and participation in the study did not influence the medical management of the patient. It was not possible to link the telephone number dialled and the respondent's data in the study database. All data collected was kept confidential and anonymous.

\section{Competing interests}

AEH, FA, and LT are employees of and shareholders in GSK, which funded the SNAPSHOT study. HT is currently also employed by GSK but at the time the study was conducted he participated in his capacity as Professor of medicine and allergy at the University of Cairo. AL is a director of MS Health, the clinical and epidemiological research company that implemented this study on behalf of GSK. AD is a director of Foxymed, a medical communication and consultancy company which participated in the design of the study and the interpretation of the results on behalf of GSK. The authors declare to have no further conflict of interest.

\section{Publisher's Note}

Springer Nature remains neutral with regard to jurisdictional claims in published maps and institutional affiliations.

\section{Author details}

${ }^{1}$ The Medical School, Cairo University, Cairo, Egypt. ${ }^{2}$ Department of Chest Diseases, Division of Allergy and Immunology, Ankara University, School of Medicine, Ankara, Turkey. ${ }^{3}$ Chest Medicine Department, Zain Hospital, Kuwait City, Kuwait. ${ }^{4}$ College of Medicine, University of Sharjah, Sharjah, United Arab Emirates. ${ }^{5}$ Department of Pulmonary Medicine, Rashid Hospital, Dubai, United Arab Emirates. ${ }^{6}$ Foxymed, Paris, France. ${ }^{7}$ MS Health, Rabat, Morocco. ${ }^{8}$ GlaxoSmithKline, PO Box 50199, Dubai, United Arab Emirates.

\section{Received: 9 September 2017 Accepted: 9 April 2018} Published online: 11 May 2018

\section{References}

1. The Global Asthma Report 2014. In.: Global asthma network; 2014.

2. Global surveillance, prevention and control of chronic respiratory diseases: a comprehensive approach. In.: World Health Organisation; 2007.

3. Worldwide variation in prevalence of symptoms of asthma, allergic rhinoconjunctivitis, and atopic eczema: ISAAC. The international study of asthma and allergies in childhood (ISAAC) steering committee. Lancet (London, England). 1998;351(9111):1225-32.
4. Lai CK, Beasley R, Crane J, Foliaki S, Shah J, Weiland S. Global variation in the prevalence and severity of asthma symptoms: phase three of the international study of asthma and allergies in childhood (ISAAC). Thorax. 2009:64(6):476-83.

5. Variations in the prevalence of respiratory symptoms, self-reported asthma attacks, and use of asthma medication in the European Community respiratory health survey (ECRHS). Eur Respir J. 1996;9(4): 687-95.

6. Witvliet M. World health survey: a useful yet underutilized Global Health data source. Austin J Public Health Epidemiology. 2014;1(3):1012.

7. Jarvis D, Newson R, Lotvall J, Hastan D, Tomassen P, Keil T, Gjomarkaj M, Forsberg B, Gunnbjornsdottir M, Minov J, et al. Asthma in adults and its association with chronic rhinosinusitis: the GA2LEN survey in Europe. Allergy. 2012;67(1):91-8.

8. Rabe KF, Adachi M, Lai CK, Soriano JB, Vermeire PA, Weiss KB, Weiss ST. Worldwide severity and control of asthma in children and adults: the global asthma insights and reality surveys. J Allergy Clin Immunol. 2004;114(1):40-7.

9. Sekerel BE, Gemicioglu B, Soriano JB. Asthma insights and reality in Turkey (AIRET) study. Respir Med. 2006;100(10):1850-4.

10. Khadadah M, Mahboub B, Al-Busaidi NH, Sliman N, Soriano JB, Bahous J. Asthma insights and reality in the Gulf and the near east. Int J Tuberc Lung Dis. 2009;13(8):1015-22.

11. Emri S, Turnagol H, Basoglu S, Bacanli S, Guven GS, Aslan D. Asthma-like symptoms prevalence in five Turkish urban centers. Allergol Immunopathol. 2005;33(5):270-6.

12. Kurt E, Metintas S, Basyigit I, Bulut I, Coskun E, Dabak S, Deveci F, Fidan F, Kaynar $\mathrm{H}$, Kunt Uzaslan $\mathrm{E}$, et al. Prevalence and risk factors of allergies in Turkey (PARFAIT): results of a multicentre cross-sectional study in adults. Eur Respir J. 2009;33(4):724-33.

13. OECD. Health at a Glance: Europe 2012. Paris: OECD Publishing; 2012. http:// dx.doi.org/10.1787/9789264183896-en.

14. To T, Stanojevic S, Moores G, Gershon AS, Bateman ED, Cruz AA, Boulet LP. Global asthma prevalence in adults: findings from the cross-sectional world health survey. BMC Public Health. 2012;12:204.

15. Tug T, Acik Y. Prevalence of asthma, asthma-like and allergic symptoms in the urban and rural adult population in eastern Turkey. Asian Pac J Allergy Immunol/Allergy Immunol Soc Thailand. 2002;20(4):209-15.

16. Alsowaidi $S$, Abdulle $A$, Bernsen $R$, Zuberbier T. Allergic rhinitis and asthma: a large cross-sectional study in the United Arab Emirates. Int Arch Allergy Immunol. 2010;153(3):274-9.

17. Mahboub BH, Al-Hammadi S, Rafique M, Sulaiman N, Pawankar R, Al Redha Al, Mehta AC. Population prevalence of asthma and its determinants based on European Community respiratory health survey in the United Arab Emirates. BMC Pulm Med. 2012;12:4

18. Moradi-Lakeh M, El Bcheraoui C, Daoud F, Tuffaha M, Kravitz H, Al Saeedi M, Basulaiman M, Memish ZA, AlMazroa MA, Al Rabeeah AA, et al. Prevalence of asthma in Saudi adults: findings from a national household survey, 2013. BMC Pulm Med. 2015;15:77.

19. Nafti S, Taright S, El Ftouh M, Yassine N, Benkheder A, Bouacha H, Fakhfakh $\mathrm{H}$, Ali-Khoudja M, Texier N, El Hasnaoui A. Prevalence of asthma in North Africa: the asthma insights and reality in the Maghreb (AIRMAG) study. Respir Med. 2009;103(Suppl 2):S2-11.

20. Adeloye D, Chan KY, Rudan I, Campbell H. An estimate of asthma prevalence in Africa: a systematic analysis. Croat Med J. 2013;54(6):519-31.

21. Abdelkader El Hasnaoui FA, Tariq L, Lahlou A, Du Plessis D. An omnibus approach to assess the prevalence, burden and quality of life of multiple diseases in the general population: the snapshot program in the Middle East. Med Res Archives. 2018;6:2.

22. Rabin R, de Charro F. EQ-5D: a measure of health status from the EuroQol group. Ann Med. 2001;33(5):337-43.

23. Dolan P. Modeling valuations for EuroQol health states. Med Care. 1997 35(11):1095-108.

24. Annesi-Maesano I, Didier A, Klossek M, Chanal I, Moreau D, Bousquet J. The score for allergic rhinitis (SFAR): a simple and valid assessment method in population studies. Allergy. 2002;57(2):107-14.

25. Duc AN, Wolbers M. Weighted analysis of composite endpoints with simultaneous inference for flexible weight constraints. Stat Med. 2017; 36(3):442-54.

26. Min SY, Park DW, Yun SC, Kim YH, Lee JY, Kang SJ, Lee SW, Lee CW, Kim JJ, Park SW, et al. Major predictors of long-term clinical outcomes after coronary revascularization in patients with unprotected left main coronary 
disease: analysis from the MAIN-COMPARE study. Circ Cardiovasc Interv. 2010:3(2):127-33.

27. Rabe KF, Vermeire PA, Soriano JB, Maier WC. Clinical management of asthma in 1999: the asthma insights and reality in Europe (AIRE) study. Eur Respir J. 2000;16(5):802-7.

28. Bourdin A, Doble A, Godard P. The asthma insights and reality in the Maghreb (AIRMAG) study: perspectives and lessons. Respir Med. 2009; 103(Suppl 2):S38-48.

29. Lai CK, De Guia TS, Kim YY, Kuo SH, Mukhopadhyay A, Soriano JB, Trung PL, Zhong NS, Zainudin N, Zainudin BM. Asthma control in the Asia-Pacific region: the asthma insights and reality in Asia-Pacific study. J Allergy Clin Immunol. 2003;111(2):263-8.

30. Abdul Salam A, Elsegaey I, Khraif R, Al-Mutairi A. Population distribution and household conditions in Saudi Arabia: reflections from the 2010 census. SpringerPlus. 2014;3:530.

31. Hamzacebi H, Unsal M, Kayhan S, Bilgin S, Ercan S. Prevalence of asthma and respiratory symptoms by age, gender and smoking behaviour in Samsun, north Anatolia Turkey. Tuberkuloz ve toraks. 2006;54(4):322-9.

32. Nicolaou N, Siddique N, Custovic A. Allergic disease in urban and rural populations: increasing prevalence with increasing urbanization. Allergy. 2005:60(11):1357-60

33. United Nations DoEaSA, Population Division: World urbanization prospects: the 2014 revision, highlights (ST/ESA/SER.A/352). In.; 2014

34. Center for International Earth Science Information Network - CIESIN Columbia University, International Food Policy Research Institute - IFPRI, The World Bank, Centro Internacional de Agricultura Tropical - CIAT: Global ruralurban mapping project, version 1 (GRUMP), urban extents, Kuwait. In. Palisades, NY: CIESIN, Columbia University: NASA Socioeconomic Data and Applications Center (SEDAC); 2009.

35. Center for International Earth Science Information Network - CIESIN Columbia University, International Food Policy Research Institute - IFPRI, The World Bank, Centro Internacional de Agricultura Tropical - CIAT: Global ruralurban mapping project, version 1 (GRUMP), urban extents, Saudi Arabia. In. Palisades, NY: CIESIN, Columbia University: NASA Socioeconomic Data and Applications Center (SEDAC); 2009.

36. Leynaert B, Sunyer J, Garcia-Esteban R, Svanes C, Jarvis D, Cerveri I, Dratva J, Gislason T, Heinrich J, Janson C, et al. Gender differences in prevalence, diagnosis and incidence of allergic and non-allergic asthma: a populationbased cohort. Thorax. 2012;67(7):625-31.

37. de Marco R, Locatelli F, Sunyer J, Burney P. Differences in incidence of reported asthma related to age in men and women. A retrospective analysis of the data of the European respiratory health survey. Am J Respir Crit Care Med. 2000;162(1):68-74.

38. van den Berge M, Heijink HI, van Oosterhout AJ, Postma DS. The role of female sex hormones in the development and severity of allergic and nonallergic asthma. Clin Exp Allergy: J British Soc Allergy Clin Immunol. 2009; 39(10):1477-81.

39. Lundback $B$, Lindberg $A$, Lindstrom $M$, Ronmark $E$, Jonsson $A C$, Jonsson $E$, Larsson LG, Andersson S, Sandstrom T, Larsson K. Not 15 but 50\% of smokers develop COPD?-report from the obstructive lung disease in northern Sweden studies. Respir Med. 2003;97(2):115-22.

40. Khattab A, Javaid A, Iraqi G, Alzaabi A, Ben Kheder A, Koniski ML, Shahrour N, Taright S, Idrees M, Polatli M, et al. Smoking habits in the Middle East and North Africa: results of the BREATHE study. Respir Med. 2012;106(Suppl 2):S16-24.

41. Scadding G, Walker S. Poor asthma control?-then look up the nose. The importance of co-morbid rhinitis in patients with asthma. Prim Care Respir J: J Gen Practice Airways Group. 2012;21(2):222-8.

42. Bousquet J, Van Cauwenberge P, Khaltaev N. Allergic rhinitis and its impact on asthma. J Allergy Clin Immunol. 2001;108(5 Suppl):S147-334.

43. Organisation WH: Global status report on noncommunicable diseases 2014. In.; 2014.

44. Ng M, Fleming T, Robinson M, Thomson B, Graetz N, Margono C, Mullany EC, Biryukov S, Abbafati C, Abera SF, et al. Global, regional, and national prevalence of overweight and obesity in children and adults during 19802013: a systematic analysis for the global burden of disease study 2013. Lancet (London, England). 2014;384(9945):766-81.

45. Beuther DA, Sutherland ER. Overweight, obesity, and incident asthma: a meta-analysis of prospective epidemiologic studies. Am J Respir Crit Care Med. 2007;175(7):661-6.

46. Iribarren C, Tolstykh IV, Eisner MD. Are patients with asthma at increased risk of coronary heart disease? Int J Epidemiol. 2004;33(4):743-8.
47. Appleton SL, Ruffin RE, Wilson DH, Taylor AW, Adams RJ. Asthma is associated with cardiovascular disease in a representative population sample. Obes Res Clin Pract. 2008;2(2):71-142.

48. Liang B, Yi Q, Feng Y. Association of gastroesophageal reflux disease with asthma control. Dis Esophagus : official journal of the International Society for Diseases of the Esophagus / ISDE. 2013;26(8):794-8.

49. Iribarren C, Tolstykh IV, Miller MK, Sobel E, Eisner MD. Adult asthma and risk of coronary heart disease, cerebrovascular disease, and heart failure: a prospective study of 2 matched cohorts. Am J Epidemiol. 2012;176(11): 1014-24.

50. Chen MH, Li CT, Tsai CF, Lin WC, Chang WH, Chen TJ, Pan TL, Su TP, Bai YM. Risk of dementia among patients with asthma: a nationwide longitudinal study. J Am Med Dir Assoc. 2014;15(10):763-7.

51. Jones PW, Quirk FH, Baveystock CM, Littlejohns P. A self-complete measure of health status for chronic airflow limitation. The St. George's respiratory questionnaire. Am Rev Respir Dis. 1992;145(6):1321-7.

52. Juniper EF, Guyatt GH, Ferrie PJ, Griffith LE. Measuring quality of life in asthma. Am Rev Respir Dis. 1993;147(4):832-8.

53. Marks GB, Dunn SM, Woolcock AJ. A scale for the measurement of quality of life in adults with asthma. J Clin Epidemiol. 1992;45(5):461-72.

54. Hyland ME, Finnis S, Irvine SH. A scale for assessing quality of life in adult asthma sufferers. J Psychosom Res. 1991;35(1):99-110.

55. Maille AR, Kaptein AA, Koning CJ, Zwinderman AH. Developing a quality-oflife questionnaire for patients with respiratory illness. Monaldi archives for chest disease = Archivio Monaldi per le malattie del torace. 1994;49(1):76-8.

56. Creer TL, Wigal JK, Kotses H, McConnaughy K, Winder JA. A life activities questionnaire for adult asthma. J Asthma : official journal of the Association for the Care of Asthma. 1992;29(6):393-9.

57. Bousquet J, Knani J, Dhivert H, Richard A, Chicoye A, Ware JE Jr, Michel FB. Quality of life in asthma. I. Internal consistency and validity of the SF-36 questionnaire. Am J Respir Crit Care Med. 1994;149(2 Pt 1):371-5.

58. Lloyd A, Price D, Brown R. The impact of asthma exacerbations on healthrelated quality of life in moderate to severe asthma patients in the UK. Prim Care Respir J: journal of the General Practice Airways Group. 2007;16(1):22-7.

59. Chen H, Gould MK, Blanc PD, Miller DP, Kamath TV, Lee JH, Sullivan SD. Asthma control, severity, and quality of life: quantifying the effect of uncontrolled disease. J Allergy Clin Immunol. 2007:120(2):396-402.

60. Hazell M, Frank T, Frank P. Health related quality of life in individuals with asthma related symptoms. Respir Med. 2003:97(11):1211-8.

\section{Ready to submit your research? Choose BMC and benefit from:}

- fast, convenient online submission

- thorough peer review by experienced researchers in your field

- rapid publication on acceptance

- support for research data, including large and complex data types

- gold Open Access which fosters wider collaboration and increased citations

- maximum visibility for your research: over $100 \mathrm{M}$ website views per year

At BMC, research is always in progress.

Learn more biomedcentral.com/submissions 